\title{
Analysis of Policy Instruments for Enhanced Competition in Spectrum Auction
}

\author{
Junwhan Kim, Achla Marathe, Guanhong Pei, Sudip Saha, Balaaji SP Subbiah, Anil Kumar S. Vullikanti \\ Network Dynamics and Simulation Science Laboratory \\ Virginia Bioinformatics Institute \\ Virginia Tech \\ Blacksburg, VA 24061, USA \\ E-mail: \{junwhan, amarathe, somehi, ssaha, basp, akumar\}@vbi.vt.edu
}

\begin{abstract}
Market based spectrum allocation should be competitive and economically efficient to effectively use the spectrum. Yet infrastructure markets have a tendency to become natural monopolies or oligopoly due to the high fixed costs and inherent economies of scale. Instruments such as set-asides, bidding credits, spectrum caps, band plan and auction designs are some of the market-based solutions that can enhance competition by incentivizing new entrants in these types of markets. In this paper, we focus on the "set-aside" instrument and study its role as a policy instrument to promote competition and encourage entry of new enterprenuers. The experimental results show that "setaside" can be a powerful instrument and its impact depends upon the number of licenses that are set-aside versus the number of new entrants in the market as well as the level of competitiveness of the new entrants. We use a three factorial experimental design and find that contrary to our expectation, the total revenue generated by FCC does not necessarily decrease by having setasides. As the number of new entrants increase and the set-asides decrease, the average total revenue raised through the sale of licenses can be more than the base case.
\end{abstract}

\section{INTRODUCTION}

The competitiveness of the telecommunication industry can be assessed by the number of service providers and the ease with which new entrants can enter the market. The market and the policy makers need to ensure that the barriers to entry are addressed and appropriate incentives exist to attract new entrants in the market. The telecom service providers need to make a substantial investment in physical infrastructure such as base stations, switches, antennas, battery, transceivers etc. in order to be operational and be able to serve the load. These kinds of costs are typically considered to be fixed and sunk. For a new entrant, this investment represents a high risk which can be better managed by sharing infrastructure with the existing providers. Sharing reduces risks, costs, and duplication.

Driven by these incentives, mergers and acquisitions of telecom groups are common, e.g. merger of SBC and AT\&T and acquisition of MCI by Verizon in 2005; the attempt to merge AT\&T and T-Mobile in 2011 etc. If the regulatory authorities had allowed the AT\&T and T-Mobile merger to go through, it would have reduced the number of major wireless carriers in the US from 4 to 3. With this merger, Verizon and AT\&T together would have owned $80 \%$ of the US market share [1], [2] and reduced competition drastically. In case of infrastructural markets, reliance on the market forces alone is often not enough to maintain or enhance competition among the providers. Government can intervene by applying taxes, subsidies, or other policy instruments to promote competition or bring new entrants to the market. Infrastructure markets face natural barriers to entry due to high fixed costs and set up costs but such barriers reduce innovation and customer care to the detriment of the industry's advancement.

If the antitrust laws do not stop these mergers and the rising concentration of power, one can design market based instruments to assure competition and economic efficiency. As pointed out in [3], [4], instruments such as set-asides, bidding credits, spectrum caps, band plan and auction designs are some of the market based solutions that can enhance competition by incentivizing new entrants. Set-asides are the number of licenses that have been set-aside for a particular type of bidder, e.g. new entrants in this case. This instrument guarantees that the new entrants will win at least the "set-aside" licenses.

In case of "bidding credits", particular type of bidders get a percentage discount on any winning bids. "Spectrum caps" limit the amount of spectrum that can be held in a geographical area and typically allows the new entrants to bid for a greater quantity of the newly available spectrum than incumbents. Bidding credit and spectrum cap enable the new entrants in obtaining spectrum but they prohibit efficient aggregation of spectrum.

"Band plan" refers to the slicing of the spectrum into blocks and partitioning into geographical areas. Coordinated band plans across countries promote entry by international providers. Auction design uses features like bid format, reservation price, information policy etc. to influence the outcome of the auction. Different combinations of these features favor different types of providers [3].

There is a natural asymmetry between the incumbent and the new entrant when it comes to bidding competitively, owning infrastructure, having economies of scale and the market share. The incumbents get synergy value from obtaining additional spectrum in the market, which motivates them to bid aggressively and deter entry. The policy instruments suggested by Crampton (2011) are designed to make the playing field more even for the new entrants. In the short term these instruments are likely to result in higher costs and overall lower market 
efficiency but in the long run, more innovation and growth of the industry.

This paper studies one such market instrument in detail. It analyzes the role of "set-asides" as an instrument available to the regulator to promote competition and encourage entry of new enterprenuers. Interesting research questions pertaining to set-asides include: who should qualify as a new entrant, what fraction of market share should the provider have in order to be a new entrant; what fraction of licenses should be set-aside from the available licenses; should it be proportionally the same as is available to the incumbents? What if all the setasides do not get sold to the new entrants, who should they be offered to and at what price? This research attempts to answer some of these questions.

An individual based simulation system, SIGMASPECTRUM [5], [6] is used to generate a synthetic spectrum demand model for the region of Portland, OR, and experiment with the "set-asides" in the primary market for this region; an auction mechanism by Ausubel is used to sell licenses to the wireless service providers in the primary market [5], [6]. A 3 factorial experimental design analyzes the effect of different parameter settings for the number of set-asides, number of new entrants and marginal valuations on the response variables as measured by market revenue, number of licenses won, and surplus capacity.

For the synthetic spectrum demand model of [5], [6] for Portland, OR, the results show that in the presence of setasides, the average revenue from the sale of licenses drops since new entrants are not competitive bidders. However the revenue increases with the increase in the number of new entrants for the same number of set-asides, and with the decrease in the number of set-asides for the same number of new entrants, see Figure 1. If the competition among the new entrants for the set-asides is very high, i.e. for 2 set-asides there are 4 to 6 new entrants, the average revenue is even higher than the base case of no set-asides. This is due to the fact that the competition among the incumbents becomes even more aggressive and the regular licenses are sold at a much higher price compared to the base case. We note, however, that the above results are specific for the spectrum demand model as well as the primary market we study here. More research is needed into the sensitivity of the results to other models and auction mechanisms.

The remainder of the paper is organized in the following manner. In Section II, we provide the past and related efforts. In Section III, we give a brief overview of our model. In Section IV, we discuss simulation setup. Our results are discussed in Section V. The final section concludes the paper.

\section{RELATED WORK}

According to the recent media reports, telecom industry has been more active than even the financial services industry in terms of mergers and acquisitions (M\&A). In 2009-2010, CenturyLink, Frontier and Windstream made majority of the M\&A deals. Their declining revenue due to cable defection and wireless substitution was expected to be compensated in strength by acquiring other telecoms. Similarly, in the international market, Dutch service provider KPN bought out the wholesale voice provider iBasis, the French conglomerate Vivendi bought up fixed line operator GVT [7].

In Canada, the telecom panel review concluded that reduced competition, higher prices, less innovation, lower uptake and lower rates of usage can be explained by the fact that all three national wireless service providers are owned by providers who are responsible for the wireline services also. The Canadian panel recommended that instruments such as spectrum caps and set-asides may be used to provide opportunities to the new entrants and the antenna towers may be shared to enable competitive entry [8]. In Canada, a new entrant is defined as an entity which holds less than $10 \%$ of the national wireless market revenue. Any licenses won through the set-aside may not be transferred to companies that do not meet the criteria of a new entrant for a period of 5 years from the date of issuance.

The work by Cramton et al. [3] is closest in spirit to this research. It uses a variety of options to enhance competition e.g. set-aside, bidding credits, spectrum caps, band plan, auction design, and antitrust enforcement. These options enhance competition in the auction. The purpose of the paper [3] is to better build and understand market instruments that can help with increased competition. However the analysis of these instruments is not exhaustive. The critical factors that affect competition is the number of new entrants, number of total licenses available, number of set-asides and the marginal valuations for the licenses. The role of each of these factors need to be understood independently as well as in relation to each other.

Our experiment consists of two steps. The first step divides the providers into incumbents and new entrants. The licenses are divided into regular licenses and set-asides. An ascending bid auction [9] is run for all the regular licenses in which all providers can participate. The second step consists of auction where only the set-asides are offered and where only the new entrants can participate. A parametric experimental design plays with different values of new entrants, number of set asides and the marginal values to study how this instrument can be used for different policy settings.

\section{Modeling Overview}

This research uses a first-principles based approach to create demand for the wireless spectrum at a detailed spatio-temporal scale for the city of Portland, Oregon [5], [10], [11]. The individualistic demand profiles are constructed by generating a synthetic population for Portland, assigning a daily set of activities to each individual in the city and determining locations for each of the activities for each of the individuals using a gravity model. A mobility model moves the synthetic individuals throughout the city as they carry out their daily set of activities.

A social network based on the colocation of individuals is developed which is further used to determine who calls whom and when. The locations of the people helps determine the load on the appropriate base stations. Details on the generation of 
synthetic social network and spectrum demand generation can be found in [5], [10], [12], [13]. Other models that study spectrum usage at urban scales include [5], [14]-[17].

The mobility model is combined with a model for device ownership by individuals in the population. This is based on a data set from the CDC's NHIS survey [18], which uses demographic variables, such as age, income level, employment status, and gender. Finally, this is combined with calling pattern models for individuals, which preserve aggregate call characteristics, such as the arrival rates and duration distributions, e.g., from [16], [17].

We study the spatio-temporal variation innetwork traffic at the level of cells, which are defined as the voronoi regions associated with a real data set of 2138 base station locations in Portland area; a Voronoi cell for each cell tower consists of all the points that are closer to it than any other cell tower. We track and project the mobility of people to these cells, such that for each individual, based on his/her mobility and activity, we record the entrance and departure times of each cell on his/her trajectory.

The session generator module creates a series of call sessions based on the following constraints: the caller and callee must be in the same social network; the call arrival rate and the call duration follow the distribution and parameters given in [16], [19]. Finally the load generator aggregates the call sessions based on the location of the individuals and cell towers and determines the spatial temporal load.

\section{A. The Market Model}

We use SigMA-SPECTRUM modeling environment to allocate the licenses in the primary market. Detailed information on this model can be found in [13], [20], [21].

The Sigma-Spectrum module implements Ausubel's auction mechanism to clear the trades [9], [13] and allocate the licenses. In this ascending bid auction, the auctioneer starts with the announcement of a minimum price and keeps raising the price in increments till the total market demand is no greater than the FCC supply. If at any price, the sum of rivals' demand of any bidder $i$ is less than the supply, the difference is sold to bidder $i$ at the current price. This continues until there is no excess demand.

\section{B. Marginal Valuations}

The marginal value of the licenses is determined using a common value model. In this setting, each provider makes an independent assessment of the value of each license even though the licenses are worth the same to everyone. The providers draw their independent values randomly from a uniform distribution $(1,10)$ and ensure that each has a downward sloping demand curve for the licenses.

Table I shows the marginal valuation for each of the licenses for each of the providers. It also shows the number of licenses needed by each provider and the priority list for the providers that are candidates for becoming new entrants. The valuations have been calculated the same way as in [13].
In case of set-asides, the new entrants adjust their marginal valuations downwards by $0 \%,-10 \%$ and $-20 \%$ to reflect their non-competitiveness in the market (see Table II). The $0 \%$ scenario is simulated to show that if the new entrants were just as competitive as the incumbents and yet are given the advantage of set-asides, what might happen to the various market response variables and their measurements. The other two parameter values, i.e. $-10 \%$ and $-20 \%$ are expected to capture their non-competitiveness as new entrants.

The auction determines the clearing price and the winner for each license based on the marginal valuations. After the market clearing is done, measurements are taken on the revenue raised by the FCC, the unserved demand, the valuations and the licenses won by each provider to evaluate the performance of set-asides as a policy instrument.

\section{The Experimental Setup}

As mentioned above, we design a 3 factorial experiment to study the role of the number of new entrants, number of set-asides and the change in marginal valuations by the new entrants given the set-asides. Since different parameter setting on each of these factors result in different outcomes, it offers the regulators a variety of policy options to get the desired results [3]. We simulate a primary spectrum market in the city of Portland where FCC is the only supplier and it has a fixed number of licenses which it has obtained at no cost.

The regulator reserves one or more of the spectrum licenses for a particular type of bidder. Bidders may be either incumbents or new entrants. The most common use is to set aside a few licenses for the new entrants, and exclude the incumbents. In our experimental setup also, only the entrants are given the opportunity to buy the set asides. An ascending auction allocates the licenses to the potential bidders. Assuming that the new entrants are not as competitive in bidding, the experiment allows them to reduce their marginal valuations of the licenses by up to $20 \%$ as compared to the base case.

The results of the set-aside experiment highly depend on the number of set-asides, new entrants, and marginal valuations. Evidently, a small number of set-aside and a large number of entrants lead to high competition. We assume that providers with the least amount of market share are candidates to become new entrants.

A complete design of experiment is run where each of the 3 factors (set-asides, entrants, and valuation) takes 3 parameters and the performance is measured against 3 response variables resulting in a total of $3 \times 3 \times 3=27$ combinations. Each of the combinations is run 25 times and then averaged to smooth out stochastic variation. All results reported here are averages over the 25 replicates. Table II shows the number of setasides, entrants, and the change in marginal valuation (MV). We consider three parameter values for each of the 3 factors.

In our model, the licenses are allocated in two iterations. All licenses are split into 2 categories; set-aside licenses and regular licenses. In the first iteration, an ascending bid auction allocates the regular licenses competitively to all the providers who want to bid. In the next iteration, only the set-asides are 
offered and only the new entrants are allowed to bid for the setasides. Results of this factorial design are compared against a base case to highlight the importance of set-asides. In the base case, there are no set-asides. All licenses are labeled regular and are allocated in the first iteration itself.

We assume that the licenses offered in the auction are all homogeneous i.e. they have the same features in terms of their bandwidth, power levels, coverage area etc. We assume that there are ten service providers $\{\mathrm{A}, \mathrm{B}, \mathrm{C} \ldots \mathrm{J}\}$ serving Portland with market shares of $25.12 \%, 18 \%, 13.54 \%, 13.3 \%, 13.03 \%$, $5.17 \%, 3.65 \%, 4.25 \%, 3.19 \%$ and $0.649 \%$ respectively. The market shares have been assigned to simulate realistic representation of market shares of the service providers Verizon, ATT, Sprint-Nextel, T-mobile etc. A demand generation module, part of the SIGMA-SPECTRUM tool, described in [5], [6] ensures that the load generated for each of the service provider matches its market share. The experiments assume that each license has a capacity of $250 \mathrm{MHz}$. This may not be realistic but the conclusions are independent of the absolute value of the license capacity and will still hold. Based on 250 $\mathrm{MHz}$ capacity, each service provider estimates the number of licenses required to serve its customers' spectrum demand in the retail market.

TABLE II: The 3 Factors: Number of Set-Asides, Entrants, and Change in Marginal Valuations (MV)

\begin{tabular}{|c|c|c|}
\hline Set-Asides & Entrants & Drop in Valuation by Entrants \\
\hline 2 & 2 & $0 \%$ \\
4 & 4 & $10 \%$ \\
6 & 6 & $20 \%$ \\
\hline
\end{tabular}

\section{AnAlysis of Results}

This section gives a brief analysis of the experimental results. The overview of the results from the 27 different combinations as well as the base case can be seen in Figure 1. It shows that as the number of new entrants increase and as the number of set-asides decrease, the average total revenue (across the 25 replicates) for the FCC increases. In all cases where the number of new entrants is more than the number of set-asides, the average total revenue is even higher than the case when there are no set-asides. This is caused by the intense competition for the fewer regular licenses left to be allocated among the incumbents and a high demand for the set-asides among the new entrants. This result holds even when the new entrants drop their marginal valuations. This implies that the set-asides do not necessarily result in lower revenue as compared to the base case. Depending upon the configuration of the number of set-asides, regular licences, new entrants and incumbents, the total revenue raised from the auction can be higher, lower or the same.

Figure 2 shows the marginal valuations for the same set of configurations. Providers A and B are the two largest providers, each with a share of $25 \%$ and $18 \%$ respectively. The entrants are I and J when only 2 new ones are considered; in case of 4 , the entrants are G, H I and J. Providers D and $\mathrm{E}$ are underserved even in base case when there are no set-asides. D needs 4 licenses but wins 3 or less and $\mathrm{E}$ needs 3 but wins 2 . The fractions are the result of the average over 25 outcomes. When set-asides are introduced, all incumbents win fewer number of licenses than the base case. The biggest incumbents'drop in \% share is more than the smaller incumbents. The new entrants unilaterally gain from the set asides. They all have doubled the chances of winning the license.

Figure 3 shows the total unserved demands under a variety of configurations. The unserved demand decreases with the increased competition. The unserved demands in case of 2 setasides and 6 new entrants is the same as the base case. When 6 new entrants compete for the 2 set-asides the competition is very high resulting in the low value of unserved demand. However, drop in marginal values does not have much impact on the unserved demand across most of the configurations. Even when the marginal valuations of the new entrants decrease by $20 \%$, its effect is countered by the increased competition, especially in case of fewer set-asides and large number of new entrants.

Figure 4 shows the number of licenses won by each provider under the base case, a case with 2 set-asides and 2 entrants and a case with 4 set-asides and 4 entrants along with 3 different marginal valuations. The two cases with 2 set-asides, 2 entrants and 4 set-asides, 4 entrants (MV-0\%) are less competitive. Entrants I and J obtain a smaller number of licenses than their require to meet their demand. Increased competition among the new entrants results in more of their demand being met. Note that the results are averaged over 25 runs and therefore can have fractional values for the number of licenses won.

To show the effectiveness of set-asides, we analyze the percentage of demand met for the 2, 4, and 6 new entrants illustrated in Figures 5, 6 and 7, respectively.

Figure 5 shows the percentage of license demand met for 3 different set-asides under 2 entrants (i.e., I and J) and the base case. The case with 2 set-asides and 2 entrants without the drop in marginal value leads to the lowest competition, reducing the percentage of demand met. In other cases, entrants I and $\mathrm{J}$ have $100 \%$ license demand met because dropping marginal values and increasing set-asides incur competition.

In Figure 6, the demand of entrants $\mathrm{G}, \mathrm{H}, \mathrm{I}$, and $\mathrm{J}$ with 2 set-asides are not fully satisfied. Also, the new entrants' demand is not satisfied when 4 set-asides are offered and MV is at $0 \%$. Meanwhile, in case of 6 new entrants, Figure 7, the demand is not fully met in spite of 6 set-asides. Entrant $\mathrm{E}$ needs 3 licenses and entrants $\mathrm{F}, \mathrm{G}, \mathrm{H}, \mathrm{I}$, and $\mathrm{J}$ require 1 license resulting in excess demand.

\section{SUMMARY AND CONCLUSIONS}

This paper analyzes the role of "set-asides" as a market instrument to promote competition and encourage new entrants into an industry that has high fixed costs and set up costs. Setasides allow the new entrants to be slightly less competitive in bidding compared to the incumbents who have economies 
TABLE I: Per unit license valuations (in \$millions) and the total spectrum required (in $\mathrm{MHz}$ ) to fulfill the demand by each service provider in Portland. The marginal valuations show that provider A is bidding for 5 licenses, provider B for 4 licenses, provider C, D and E for 3 licenses and the rest for 1 license each. The total demand for licenses is 23 and the total available supply is 12 .

\begin{tabular}{|c|ccccccc|}
\hline ID & Unit 1 & Unit 2 & Unit 3 & Unit 4 & Unit 5 & Spectrum Required & Entrant \\
\hline A & 9.172 & 7.763 & 5.736 & 3.926 & 3.426 & 1160.4 & Noncandidate \\
B & 6.429 & 5.368 & 5.211 & 2.567 & 0 & 835.2 & Noncandidate \\
C & 9.383 & 6.915 & 2.777 & 0 & 0 & 625.2 & Noncandidate \\
D & 8.335 & 7.793 & 5.386 & 0 & 0 & 614.6 & Noncandidate \\
E & 8.69 & 6.649 & 2.362 & 0 & 0 & 602 & $6^{\text {th }}$ Candidate \\
F & 5.782 & 0 & 0 & 0 & 0 & 239.2 & $5^{\text {th }}$ Candidate \\
G & 2.862 & 0 & 0 & 0 & 0 & 168.6 & $4^{\text {th }}$ Candidate \\
H & 5.123 & 0 & 0 & 0 & 0 & 196.4 & $3^{\text {rd }}$ Candidate \\
I & 4.067 & 0 & 0 & 0 & 0 & 147.4 & $2^{\text {nd }}$ Candidate \\
J & 3.135 & 0 & 0 & 0 & 0 & 30 & $1^{\text {st }}$ Candidate \\
\hline
\end{tabular}

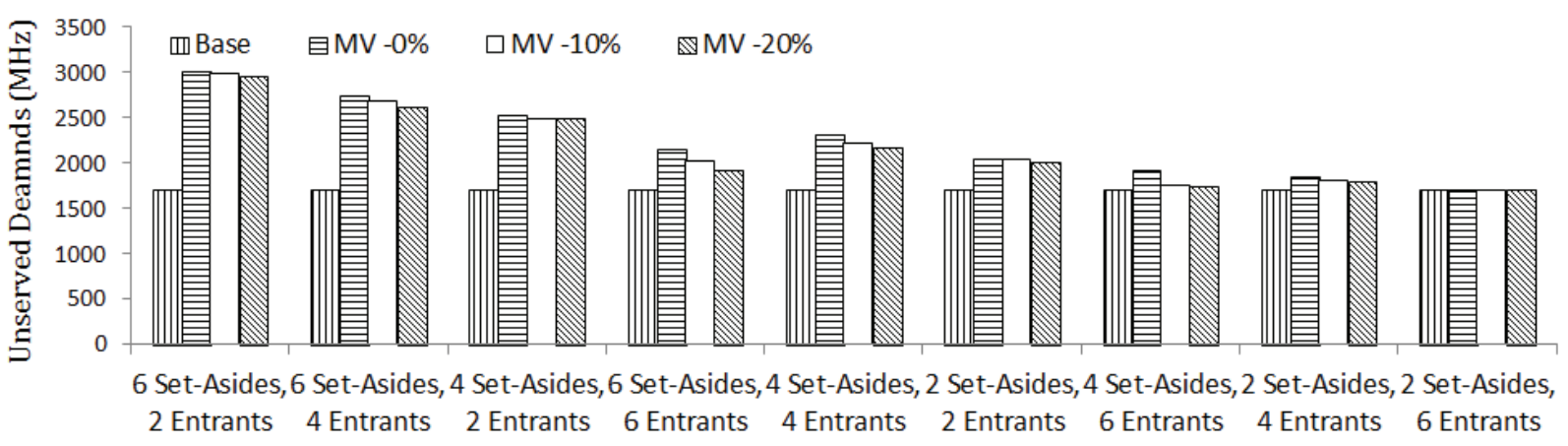

Fig. 1: This graph shows the total revenue generated for all the 27 configurations. It also shows the base case. MV refers to the marginal values. MV(-10\%) implies that the new entrants drop their marginal values by $10 \%$ compared to the base case marginal value. This drop in marginal value for the entrants is meant to reflect that the new entrants are not as competitive as the incumbents. The incumbents' marginal values stay the same under all configurations. Similarly MV(-0\%) and MV(-20\%) represent $0 \%$ and $20 \%$ drop in marginal values. The auction offers a total of 12 licenses of $250 \mathrm{MHz}$ each. The figure shows that the change in marginal value does not have large effect on total revenue except at a time when there are a few set-asides and lots of new entrants competing for them. This holds even when the new entrants drop their marginal value by $20 \$$.

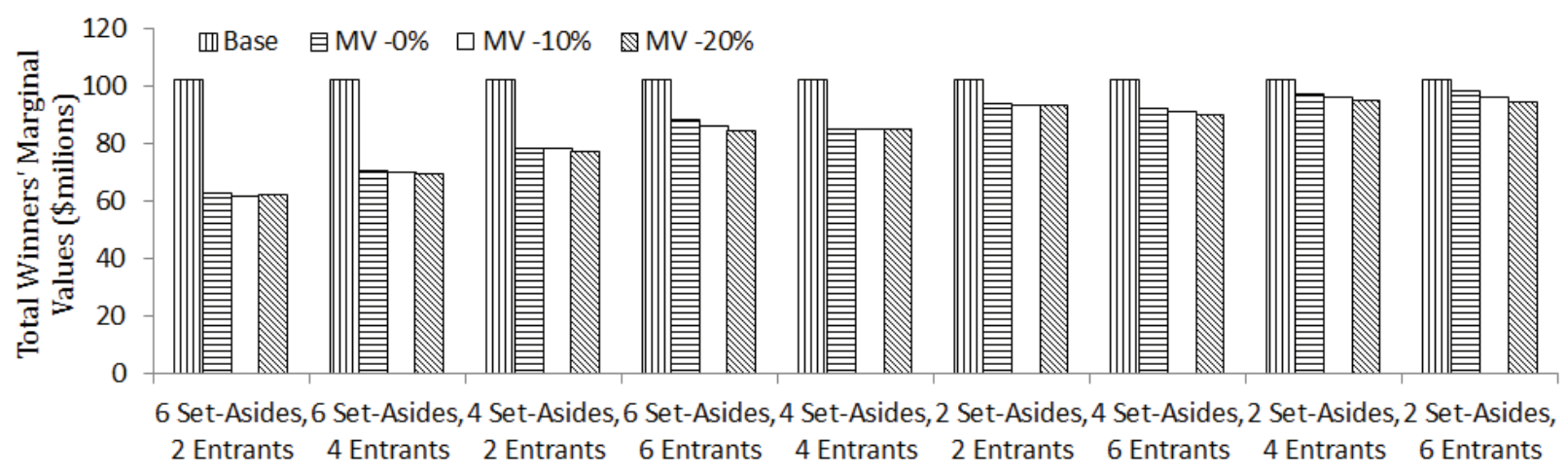

Fig. 2: This graph shows the total marginal values for all the 27 combinations as well as the base case. We observe that total marginal values of all the 27 combinations do not exceed that of the base case. Total marginal values increase as long as competition increases. The auction offers a total of 12 licenses of $250 \mathrm{MHz}$ each. 


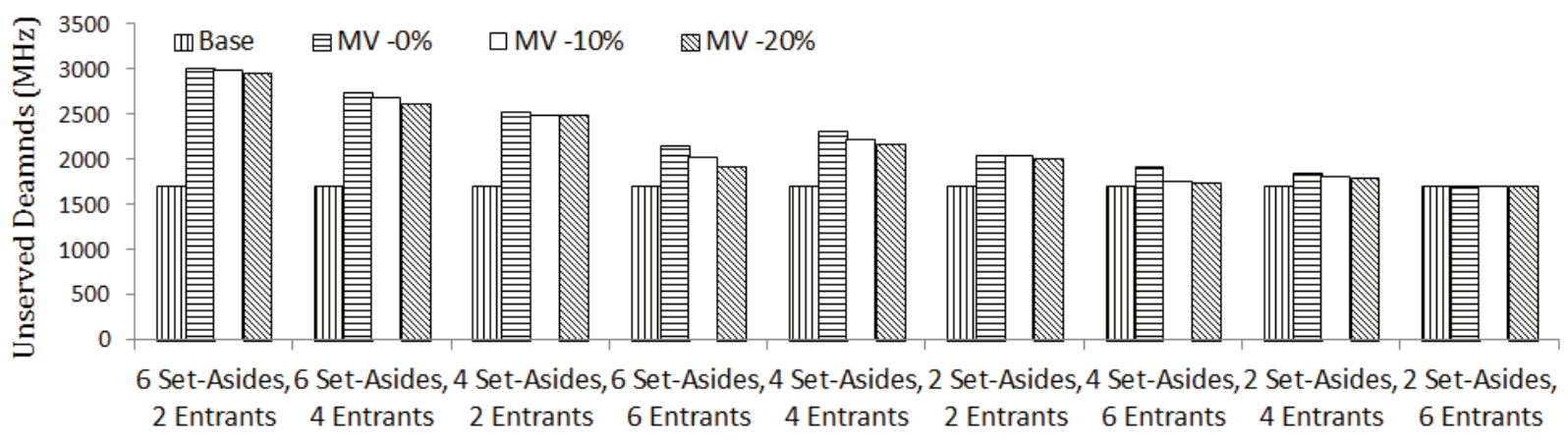

Fig. 3: This graph shows the total unserved demands for all the 27 combinations as well as the base case. We observe that total unserved demands in all 27 combinations is more than or equal to that of the base case. Total unserved demand in the most competitive settings (i.e., 2 set-asides and 6 entrants) is the same as the base case. The auction offers a total of 12 licenses of $250 \mathrm{MHz}$ each.

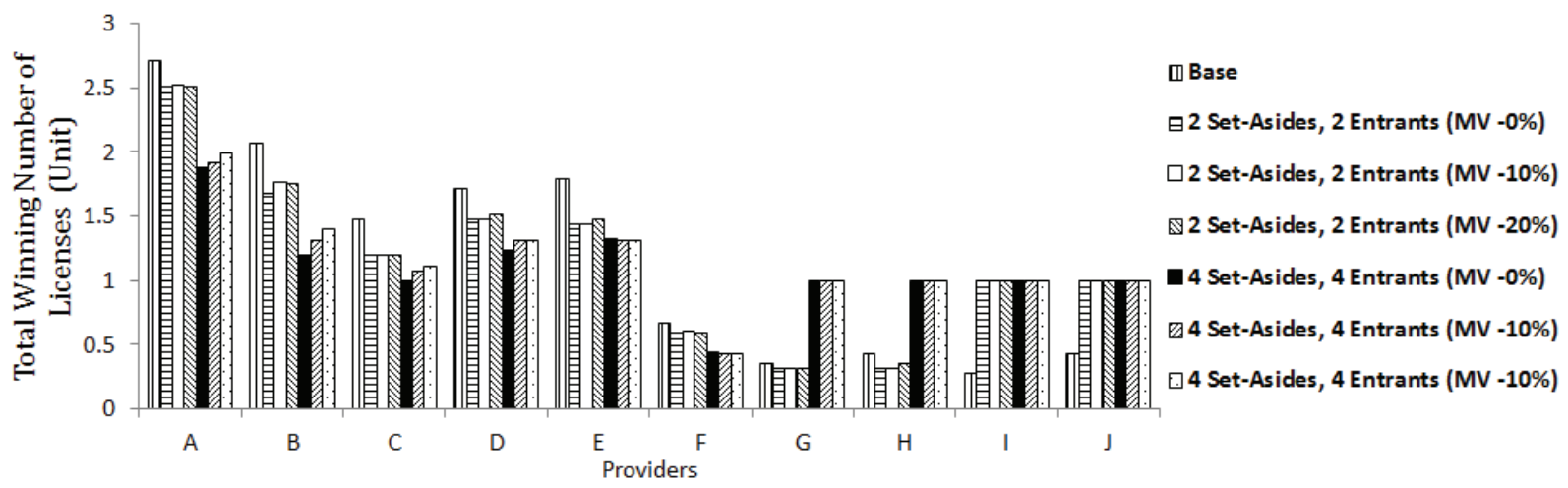

Fig. 4: This graph shows total number of licenses won under the 2 cases (i.e., 2, 4 set-asides and 2, 4 entrants) and three different marginal values (MV) for the new entrants. It also shows the base case. The auction offers a total of 12 licenses of $250 \mathrm{MHz}$ each.

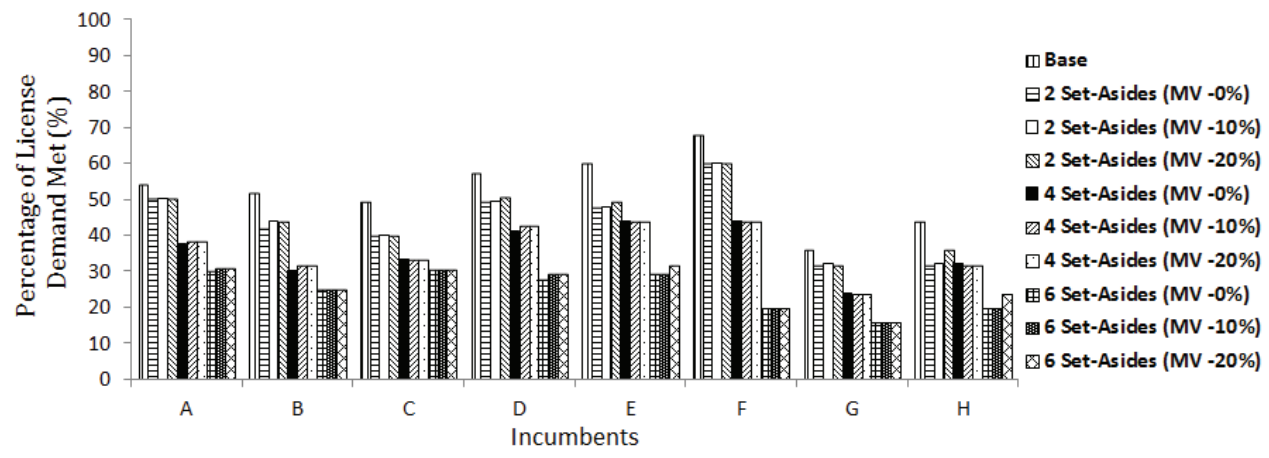

(a)

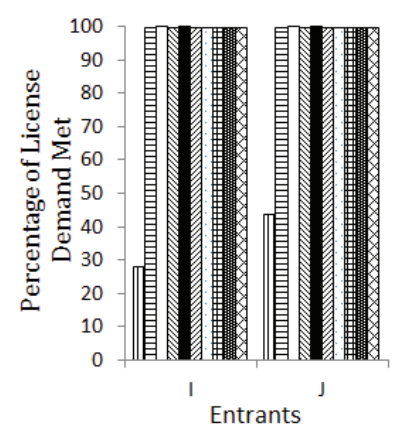

(b)

Fig. 5: Graphs (a) and (b) show the percentage of license demand met for 3 different set-asides and the base case. (a) shows the percentage of license demand met for 8 incumbents. (b) shows the percentage of license demand met for 2 entrants. The auction offers a total of 12 licenses of $250 \mathrm{MHz}$ each. 


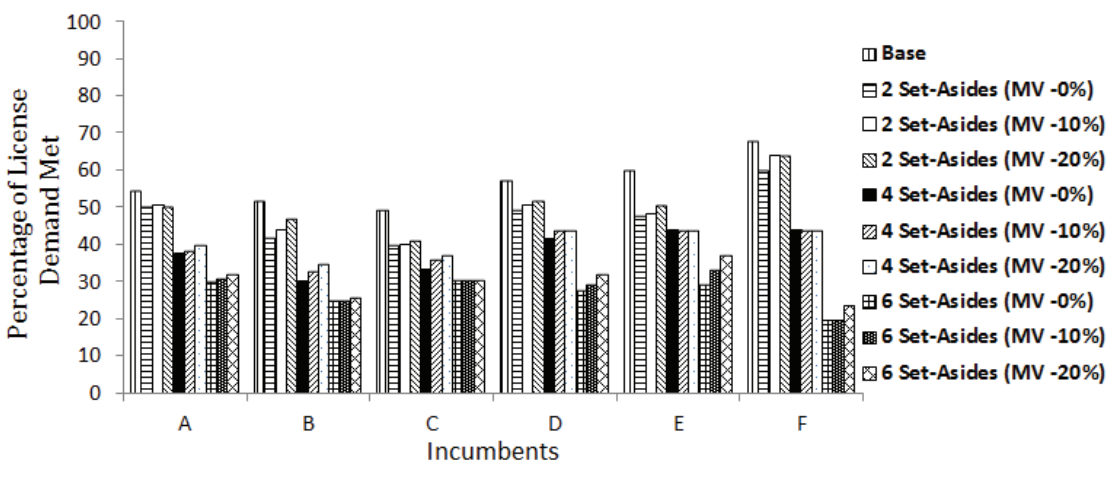

(a)

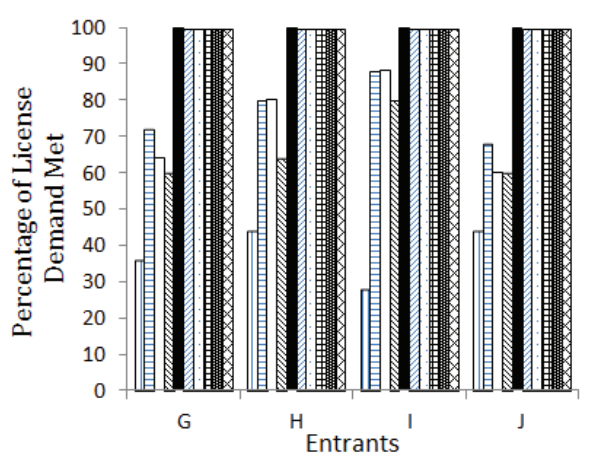

(b)

Fig. 6: Graphs (a) and (b) show the percentage of license demand met for 3 different set-asides and the base case. (a) shows the percentage of license demand met for 6 incumbents. (b) shows the percentage of license demand met for 4 entrants. The auction offers a total of 12 licenses of $250 \mathrm{MHz}$ each.

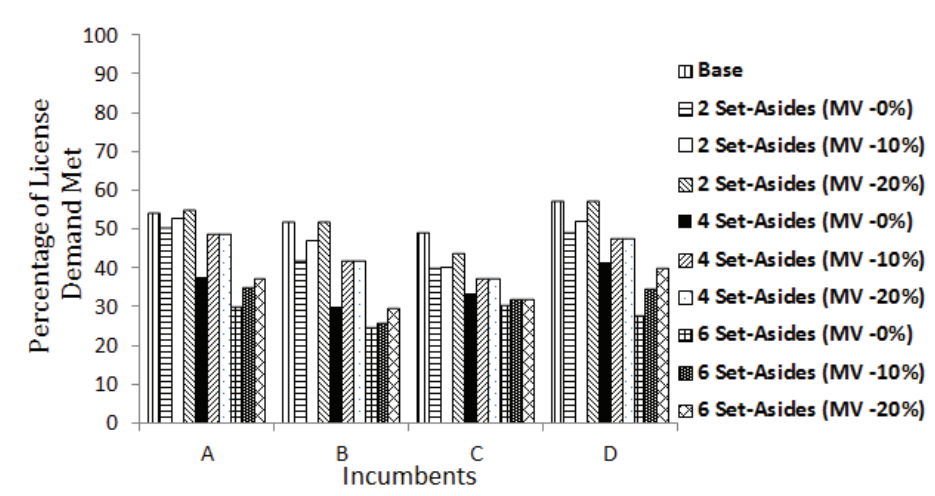

(a)

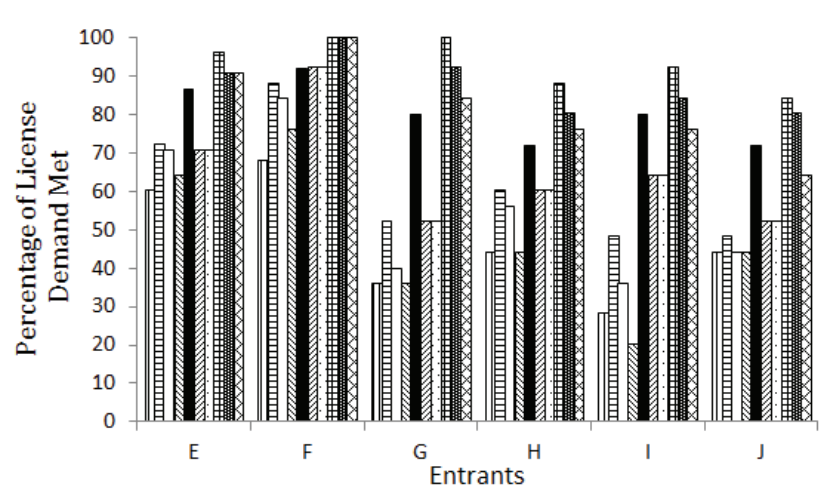

(b)

Fig. 7: Graphs (a) and (b) show the percentage of license demand met for 3 different set-asides and the base case. (a) shows the percentage of license demand met for 4 incumbents. (b) shows the percentage of license demand met for 6 entrants. The auction offers a total of 12 licenses of $250 \mathrm{MHz}$ each.

of scale and an inherent advantage. We use a 3 factorial experimental design to test various parameter values of the number of set-asides, number of new entrants and their levels of competitiveness as measured by their marginal values for the licenses. A base case is run to set up a benchmark to compare the results against. The performance of the experiments is measured by three response variables, i.e. the level of demand served, the number of licenses won and the total revenue generated by the licenses.

The results show that as the number of new entrants increase and the set-asides decrease, the average total revenue for the FCC increases even more than the base case. This is counter-intuitive since one would expect set-asides to lose revenue due to its non-competitive nature but it turns out that as fewer regular licenses are available for the incumbents, they bid more aggressively which results in overall higher revenue. This result holds whenever the total number of new entrants is larger than the number of set-asides. Depending upon the configuration of new entrants, set-asides and the marginal valuation, the total revenue raised by FCC can be higher, lower or the same. Other results show that the unserved demand increases when the competition is low among the new entrants and when their marginal valuations are noncompetitive. This study uses Ausubel's auction mechanism to allocate spectrum licenses. Meanwhile, other forms of auction (e.g. combinatorial auctions) may be used by the FCC. In future work, we will analyze how the use of different types of auction mechanisms impact the role of set-asides.

Acknowledgements: We thank our external collaborators and members of the Network Dynamics and Simulation Science Laboratory (NDSSL) for their suggestions and comments. This work has been partially supported by NSF Nets Grant CNS-0626964, DTRA R\&D Grant HDTRA1-09010017, DTRA CNIMS Grant HDTRA1-07-C-0113, NSF NETS CNS-0831633, DOE DE-SC0003957, NSF CAREER CNS0845700, NSF Netse CNS-1011769 and NSF SDCI OCI1032677. 


\section{REFERENCES}

[1] E. Savitz, "The AT\&T/T-Mobile deal: Should we fear wireless consolidation?" Forbes, Article, 2011. [Online]. Available: http://www.forbes.com/sites/ciocentral/2011/06/03/ the-attt-mobile-deal-should-we-fear-wireless-consolidation/

[2] S. M. Davidoff, "AT\&Ts battle for T-Mobile is political as well as legal," New York Times, Article, 2011. [Online]. Available: http://dealbook.nytimes.com/2011/09/ 06/atts-battle-for-t-mobile-is-political-as-well-as-legal/

[3] P. Cramton, E. Kwerel, G. L. Rosston, and A. Skrzypacz, "Using spectrum auctions to enhance competition in wireless services," Regulation2point0, Working paper 48, Mar. 2011. [Online]. Available: http://ideas.repec.org/p/ reg/wpaper/48.html

[4] S. Athey, D. Coey, and J. Levin, "Set-asides and subsidies in auctions," American Economic Journal: Microeconomics, July 2011.

[5] R. Beckman, K. Channakeshava, F. Huang, V. A. Kumar, A. Marathe, M. Marathe, and G. Pei, "Synthesis and analysis of spatio-temporal spectrum demand patterns: A first principles approach," IEEE Dynamic Spectrum Access Networks, DySPAN, April 2010.

[6] J. Kim, V. Kumar, A. Marathe, G. Pei, S. Saha, and B. Sunapanasubbiah, "Impact of geographic complementarity in dynamic spectrum access," in New Frontiers in Dynamic Spectrum Access Networks (DySPAN), 2011 IEEE Symposium on, may 2011, pp. $455-466$.

[7] S. Buckley, "Telecom M\&A rises up in 2010," Fierce Telecom, 2010. [Online]. Available: http://www.fiercetelecom.com/story/ telecom-merger-acquisition-rises-2010/2010-06-16

[8] "Policy framework for the auction for spectrum licences for advanced wireless services and other spectrum in the 2 ghz range," Inductry Canada, Technical Report, 2007. [Online]. Available: http://www.ic.gc.ca/eic/site/smt-gst. nsf/eng/sf08833.html

[9] L. M. Ausubel, "An efficient ascending-bid auction for multiple objects," American Economic Review, vol. 94, no. 5, pp. 1452-1475, December 2004.

[10] C. Barrett, D. Beckman, M. Khan, V. A. Kumar, M. Marathe, P. Stretz, T. Dutta, and B. Lewis, "Generation and analysis of large synthetic social contact networks," in Winter Simulation Conference, 2009.

[11] C. L. Barrett, R. J. Beckman, K. P. Berkbigler, K. R. Bisset, B. W. Bush, K. Campbell, S. Eubank, K. M. Henson, J. M. Hurford, D. A. Kubicek, M. V. Marathe, P. R. Romero, J. P. Smith, L. L. Smith, P. L. Speckman, P. E. Stretz, G. L. Thayer, E. V. Eeckhout, and M. D. Williams, "Transims: Transportation analysis simulation system," Technical Report LA-UR-00-1725, Los Alamos National Laboratory, 1997.

[12] Network Dynamics and Simulation Science Lab, Virginia Tech, "Synthetic data products for societal infrastructures and proto-populations," ndssl.vbi.vt.edu/opendata.
[13] R. Beckman, K. Channakeshava, F. Huang, V. A. Kumar, A. Marathe, M. Marathe, and G. Pei, "Implications of dynamic spectrum access on the efficiency of primary wireless market," IEEE Dynamic Spectrum Access Networks, DySPAN, April 2010.

[14] I. Akyildiz, W. Lee, M. Vuran, and S. Mohanty, "NeXt Generation/Dynamic Spectrum Access/Cognitive Radio Wireless Networks: A Survey," Computer Networks, pp. 2127-2159, 2006.

[15] M. A. McHenry, P. A. Tenhula, D. McCloskey, D. A. Roberson, and C. S. Hood, "Chicago spectrum occupancy measurements and analysis and a long-term studies proposal," in TAPAS, 2006.

[16] D. Willkomm, S. Machiraju, J. Bolot, and A. Wolisz, "Primary Users in Cellular Networks: A Large-Scale Measurement Study," in New Frontiers in Dynamic Spectrum Access Networks, 2008. DySPAN 2008. 3rd IEEE Symposium on, Oct. 2008, pp. 1-11.

[17] M. Seshadri, S. Machiraju, A. Sridharan, J. Bolot, C. Faloutsos, and J. Leskove, "Mobile Call Graphs: Beyond Power-law and Lognormal Distributions," in $K D D$ '08: Proceeding of the 14th ACM SIGKDD international conference on Knowledge discovery and data mining. ACM, 2008, pp. 596-604.

[18] Center for Disease Control, "National health interview survey (nhis)," http://www.cdc.gov/nchs/about/major/nhis/nhis_2007 data_release.htm.

[19] J. Kim, V. Kumar, A. Marathe, G. Pei, S. Saha, and B. Subbiah, "Modeling cellular network traffic with mobile call graph constraints," in Simulation Conference (WSC), Proceedings of the 2011 Winter, dec. 2011, pp. $3165-3177$.

[20] K. Atkins, A. Marathe, and C. Barrett, "A computational approach to modeling commodity markets," Computational Economics, vol. 30, no. 2, pp. 125-142, September 2007.

[21] K. Atkins, J. Chen, A. Kumar, M. Macauley, and A. Marathe, "Locational market power in network constrained markets," Journal of Economic Behavior and Organization, vol. 70, no. 1-2, pp. 416-430, May 2009. 